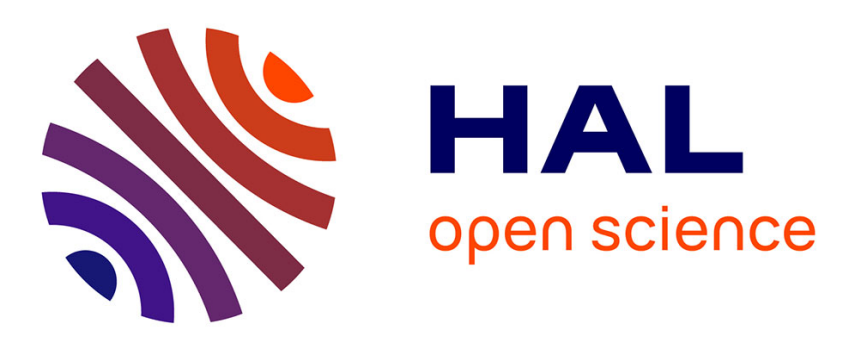

\title{
Identification of Service Platform Requirements from Value Propositions: A Service Systems Engineering Method
}

\author{
Onat Ege Adali, Baris Ozkan, Oktay Turetken, Paul Grefen
}

\section{To cite this version:}

Onat Ege Adali, Baris Ozkan, Oktay Turetken, Paul Grefen. Identification of Service Platform Requirements from Value Propositions: A Service Systems Engineering Method. 22nd Working Conference on Virtual Enterprises (PRO-VE 2021), Nov 2021, Saint-Etienne, France. pp.311-322, 10.1007/978-3-030-85969-5_28. emse-03339298

\section{HAL Id: emse-03339298 \\ https://hal-emse.ccsd.cnrs.fr/emse-03339298}

Submitted on 24 Nov 2021

HAL is a multi-disciplinary open access archive for the deposit and dissemination of scientific research documents, whether they are published or not. The documents may come from teaching and research institutions in France or abroad, or from public or private research centers.
L'archive ouverte pluridisciplinaire HAL, est destinée au dépôt et à la diffusion de documents scientifiques de niveau recherche, publiés ou non, émanant des établissements d'enseignement et de recherche français ou étrangers, des laboratoires publics ou privés. 
Adali O.E., Ozkan B., Turetken O., Grefen P. (2021) Identification of Service Platform Requirements from Value Propositions: A Service Systems Engineering Method. In: Camarinha-Matos L.M., Boucher X., Afsarmanesh H. (eds) Smart and Sustainable Collaborative Networks 4.0. PRO-VE 2021. IFIP Advances in Information and Communication Technology, vol 629. Springer, Cham. https://doi.org/10.1007/978-3030-85969-5_28

\title{
Identification of Service Platform Requirements from Value Propositions: A Service Systems Engineering Method
}

\author{
Onat Ege Adali, Baris Ozkan, Oktay Turetken, Paul Grefen \\ School of Industrial Engineering, Eindhoven University of Technology \\ PO Box 513, 5600 MB Eindhoven, the Netherlands \\ \{b.ozkan, o.e.adali, o.turetken, p.w.p.j.grefen\}@tue.nl
}

\begin{abstract}
Digital service platforms are the facilitators of value co-creation within service ecosystems. They are instrumental in the design of compelling value propositions. Despite the substantial amount of contributions for the conceptualization of digital service platforms, the methodological contributions concerning the engineering of service platforms are scarce. In this paper, we adopt a service systems perspective and present a method for the identification of digital service platform requirements. The method is driven by the value propositions that are based on the capabilities of the actors in service exchange networks. In the paper, we demonstrate the method by applying it to an international Mobility-as-a-Service platform development project.
\end{abstract}

Keywords: Service Systems Engineering, Service Platform, Requirements Engineering.

\section{Introduction}

In today's increasingly interconnected world, organizations' understanding of business is shifting away from delivering value in isolation to co-creating value in collaboration with other actors in service ecosystems [1], [2]. Digitalization is taking various roles in this transition not only through increasing connectedness beyond spatio-temporal constraints but also by influencing the way value is co-created and experienced [3]-[6]. Thus, businesses are increasingly adopting digital service platform business models which allow various actors to engage with one another for mutual benefit [7]-[9].

As with any business, value propositions are the key determinants of the success and the level of engagements between the actors over digital service platforms [5], [10]. Offering a vast amount of possibilities for effective and efficient resource mobilization [5], [11], digital service platforms provide the means for multiple actors to integrate and configure their competent resources in service systems and design compelling and complete value propositions [12]-[14]. Many digitally-enabled value proposition and service system examples can be given from successful online marketplaces, car sharing, or streaming media platforms, which reflect the multi-actor and integrative characteristic of businesses around digital service platforms well [14], [15]. 
Despite the opportunities, the design of a service platform involves many challenges regarding the identification of platform system requirements [16]. In particular, the derivation of platform requirements from value propositions is a complex task as each value proposition involves the design of a network of activities (i.e., service system functionality) and the capabilities of the service system actors thereof [9], [17]. The identification of platform system functionality in a way that supports the activities of all platform actors and in alignment with their capabilities is crucial for the realization of the value propositions and the intended value cocreation over the platform [8], [9], [18]. While there is a considerable number of contributions for the conceptualization of digital service platforms, only a few studies propose methodological guidance for deriving requirements from the value propositions to be supported by the platform.

The objective of this research is to design a method for the identification of platform requirements from value propositions in the form of use case descriptions. To design our method, we adopt a service system view on value proposition design [14], [15] and follow a situational method engineering approach [19]. More specifically, we extend the Value-Proposition driven Business Service Identification Method (VP-BSIM) [17] with the Service Requirements Engineering Method (SREM) for a Digital Service Ecosystem [16]. We demonstrate our method by applying it in a real Mobility as a Service (MaaS) digital platform development business case.

The remainder of the paper is structured as follows. Section 2 presents the related work. Section 3 elaborates on the research design followed. Section 4 introduces the proposed method and Section 5 demonstrates the application of the method in a business case. Finally, Section 6 concludes the paper with a discussion of the limitations of our approach and the opportunities for future work.

\section{Related Work}

The identification of the software requirements in a multi-actor socio-technical system context has been an interesting field of research for decades [20]. A significant number of papers followed the conventional goal-oriented approaches [21] and proposed requirements identification methods to bridge the business-level and software-level understandings of what a software system should do. However, only a few studies in the literature explicitly account for value propositions in the requirements identification process. Lessard et al. [18] adopted a service system view on value proposition design and proposed a service systems metamodel and a graphical Goal-oriented Requirement Language profile for modelling service systems. In addition, they proposed a heuristic to guide the elicitation of requirements for the service systems based on their metamodel. Immonen et al. [16] defined ecosystem members, ecosystem infrastructure, ecosystem capabilities, and digital services as the elements of a digital service ecosystem. They proposed a service requirement engineering method to support the development of a digital service in a digital ecosystem. In the design of their method, they used Use Case Analysis for the elicitation and specification of the requirements.

However, to our best knowledge, no methods exist in the literature yet that account for service system actors' resources (i.e., capabilities) and guide the translation of value propositions into platform requirements. Hence, the present study addresses this gap in the context of digital service platforms. 


\section{Research Design}

In the design and development of our method, we followed a Situational Method Engineering (SME) approach [19]. SME proposes three distinct method construction strategies: "1. from scratch strategy", "2. extension-based strategy", and "3. paradigm based strategy". Respectively the strategies relate to the construction of a novel method (1) from scratch, (2) by extending an existing base method, and (3) by abstracting a given model or instantiating a meta-model [19]. As our research objective relates to the extension of a base method, we followed the extension-based strategy. Accordingly, we considered the VP-BSIM as our base method and adapted it into a method that guides the identification of platform requirements from value propositions in the form of use case descriptions.

The base method, the VP-BSIM, guides an actor in a service system to transform their value propositions into contextualized, standardized, and modular resource reconfigurations represented by business services [17], [22]. Accordingly, the business services that the VP-BSIM yields describe the functionality of the overall service system but not in the form of software requirements that can be used in the design of a software system (i.e., a digital service platform in our context). Therefore, we extend the VP-BSIM with the means to guide the translation of service system functionality that is captured as business services into platform requirements.

In finding the right method for the extension, we searched Google Scholar (https://scholar.google.com/) for requirements engineering methods designed for service systems and/or ecosystems. Accordingly, we entered the search query ("service system" OR "service ecosystem") AND "requirements engineering method" which returned a total of 88 studies. After reviewing the title, abstract, and keywords of the studies, we selected [16] which proposes the SREM. The SREM consists of three steps and the final step: Requirements analysis, negotiation and specification relates to the translation of services defined for a service system into requirements for a service platform. The first two steps of the SREM relate to the definition of services and since the base method already includes the means to do that, we excluded the first two steps from our extension. As such, we added the procedure of the third step (i.e., method chunk) at the end of the VP-BSIM (i.e., Extended VP-BSIM) as shown in Figure 1. As such, the added method chunk takes in business service descriptions as input and transforms them to use case descriptions that describe how the digital services interact and cooperate to provide the required end-to-end digital services [16].

\section{Method Description}

In this section, we describe the Extended VP-BSIM (Figure 1) by briefly introducing the three original steps of the VP-BSIM and presenting in detail the added in the scope of our extension. For the detailed description of the three steps of the original VPBSIM, we refer the reader to [17]. 


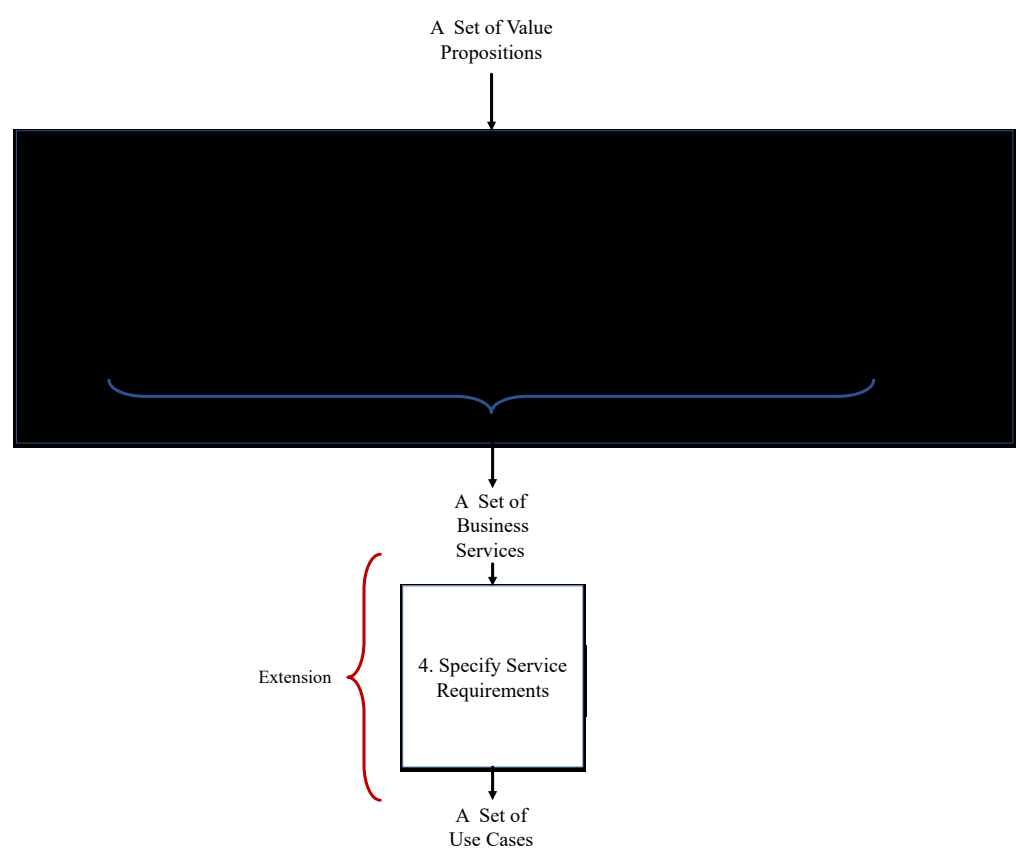

Figure 1: The Extended VP-BSIM

Step 1: Elicit the Goals that Actors pursue in the service system to Co-create Value The first step of the Extended VP-BSIM constitutes a value proposition-driven analysis to make sure that the business services to be identified enable the co-creation of value as outlined by the value proposition inputted into the method. This step uses Strategic Dependency (SD) and Strategic Rationale (SR) Modelling from i* framework [23], [24] to dissect value propositions into intentional and strategic interdependencies among actors in a service system, along with the underlying motives that each actor has in place in pursuit of these interdependencies. The outputs of this step are SD and SR Models that define the strategic and intentional relationships between the actors involved in the service system.

Step 2: Identify the Business Capabilities that Enable the Service System to Make the Value Proposition

The second step of the Extended VP-BSIM focuses on identifying the business capabilities that actors need to apply and integrate within their service system to cocreate value. This step uses Capability-Business Service Domain Mapping [25] to identify the business capabilities that fulfil the intentional and strategic interdependencies defined in Step 1. To identify the business capabilities, first, service domains (i.e., a collection of tasks called service operations that are under the control of an actor [26]) are defined. Then, each service operation under a service domain is matched with a business capability that facilitates the service operation in question. The output of this step is a set of business capabilities that enable the actors in the service system to co-create value as outlined by a value proposition. 
Step 3: Define Modular Business Services Composed of the Business Capabilities The third step focuses on defining modular business services, that describe the functionality of the service system. Furthermore, it formalizes each identified service with a description. This step uses Service Analysis with Feature Binding Technique [27] to compose the business capabilities identified in Step 2 into modular business services. This technique considers a modular service to be Self-Contained (meaning that a service should not need a service feature of another service), Stateless (meaning that a service should not require context or state information of another service), and Representative of a Domain Specific Service (meaning that a service should provide an autonomous and unique business function) [27]. The composition of the business capabilities into business services is done by following these three properties.

It should be noted while the scope of the method is the whole service system in Steps $1 \& 2$, in Step 3 the scope changes to a single actor (i.e., the actor utilizing the Extended VP-BSIM to identify its business services). Therefore, this step should be repeated for every actor (as shown with the arrow on top of Step 3 in Figure 1) to identify business services for the complete service system. The output of this step is a list of business services that describe the business functions that the service system should provide.

\section{Step 4: Specify Service Requirements}

The fourth step of the Extended VP-BSIM transforms the business service descriptions produced in Step 3 into use case descriptions that describe the behaviour of the service platform. This step uses the service system requirements engineering technique that SREM's Requirements analysis, negotiation and specification step proposes. There are two activities to be performed in this step:

Activity 4.1: Service Requirements Analysis and Negotiation:

The purpose of this activity is to determine the business services that will be used for requirements specification. As such, the business services identified in Step 3 are selected and prioritized. This requires active collaboration between stakeholders such as IT managers and business analysts to discuss and address various concerns regarding the scope of the requirements specification [16]. The third step of the VP-BSIM ensures that each business service is unique and has business potential (i.e., relates to a value proposition). Therefore, there is no need to identify and merge similar services or reject business services without business potential as the SREM originally suggests [16]. However, the stakeholders can still prioritize certain business services based on factors such as feasibility. The output of this step is a list of business services that are selected for requirements specification.

Activity 4.2: Service Requirements Specification:

The purpose of this activity is to specify service requirements in a textual or graphical format that is complete, understandable, and useful [16]. This requires several rounds of use case analysis that together transform business service descriptions into use case descriptions. This is assured in the Extended VP-BSIM by considering each business service description as a use case and the business service operations listed in each business service description as the steps of the happy flow of the use case. The outcome of this activity is a set of use case descriptions that describe the behaviour of the service platform. 


\section{The Application of the Method}

We applied our method in a real-life business case originating from the mobility domain [28] to demonstrate its validity (i.e., its ability to guide practitioners in the specification of requirements for a service platform). Below, we first introduce the business case in detail and explain the application of the method in it.

Business Case: Seamless, Optimized, \& Customized Mobility Service Provisioning In the face of ever-expanding modes of transportation and the number of transport operators, travellers have a hard time choosing the travel itinerary that complies with their needs and expectations. Besides, travellers are usually left to their own devices when passing through the different interfaces that exist between the mobility services of different transport operators. These travel management issues are even more present for international travels due to the barriers that relate to policy and language. Recognizing these issues, a European Innovation and Technology (EIT) project consortium has been focusing on the development of collaborative solutions to offer seamless, optimized, and customized mobility solutions to travellers. To do so, the consortium has envisioned a solution that integrates the resources of actors in the mobility domain, such as mobility service providers (e.g., transport operators), government bodies (e.g., cities, municipalities), traffic authorities, financial transaction providers and enhancing service providers (e.g., insurance providers). The consortium has organized a set of value proposition design workshops to realize this vision. To represent the value propositions, the SDBM Radar technique (Figure 2) is used [29], [30].

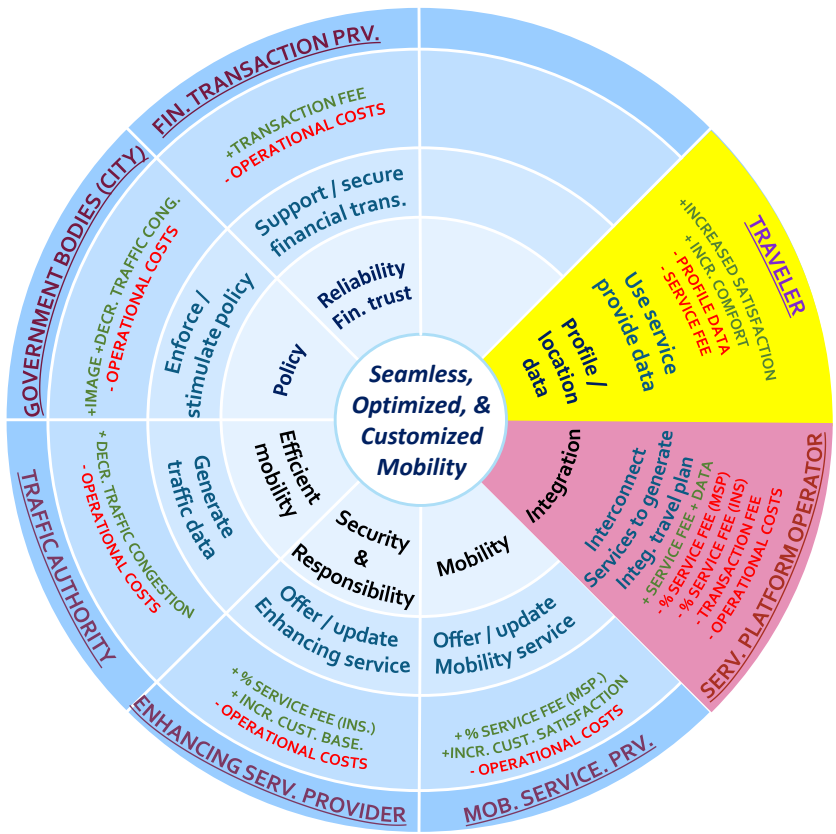

Figure 2: The Value Proposition: Seamless, Optimized, \& Customized Mobility Service Provisioning 
The resulting value proposition revolves around a service platform that enables mobility service providers to register and offer their transport services (i.e., Mobility as a Service - MaaS platform) [31]. Furthermore, the value proposition involves the inclusion of enhancing services such as insurance within the service platform. By using the platform, travellers can input their travel itinerary along with travel preferences and receive a set of recommended mobility and enhancing services that satisfies their itinerary and preferences. When travellers confirm the recommended set of transport services, the platform handles the payment and management of the tickets, and then presents all the tickets to travellers on a single application. Accordingly, the Traveller is the main beneficiary in the value proposition, who experiences the Seamless, Optimized, \& Customized Mobility Service. The initiator of the value proposition is the Service Platform Operator, who is responsible for the integration of various services. The service system is further composed of Mobility Service Providers, who provide their transport services on the platform, Enhancing Service Providers, who provide services such as insurance on the platform, Traffic Authorities, who provide traffic data used to enhance transport services, Government Bodies, who set policies to support the value proposition, and Financial Transaction Provider, who manages and secures the transactions between service providers.

\section{Application of the Method to the Business Case}

In the application of the method, we considered the Service Platform Operator as the actor (i.e., platform owner) that wants to use the method to identify its business services. Being the owner and operator of the platform, the Service Platform Operator represents the actor that orchestrates all the interactions between all the other actors in this service system. Because of this, the business services to be identified for the Service Platform Operator relate to facilitating these interactions and are directly coupled to and provisioned on the service platform. Thus, specific to our case, the business services to be identified for the Service Platform Operator represent the overall functionality that the service platform should support. This means that our case does not require iterating the third step of the method for all the actors of the service system. In general, we suggest applying the third step of the method solely for the actor that is the owner and/or the operator of the service platform as this results in the identification of business services that cover all the service system functionality. However, in the cases where a service platform is owned and/or operated by multiple actors, we suggest iterating the third step for all actors. In the following, we present the application of the method by taking the Service Platform Operator as the platform owner for the method.

\section{Application of Step 1:}

We translated the value proposition design (Figure 2) into an SR model -including also an SD model- (Figure 3) that captures the goals that actors pursue in the service system. We depicted every actor in the value proposition as an actor in the SR model as well. Furthermore, for every actor in the SR model, we defined a high-level goal (highlighted in blue in Figure 3) based on the actor's contribution to the value proposition. Lastly, we depicted the value co-creation activities of each actor in the value proposition as tasks in the SR model. 


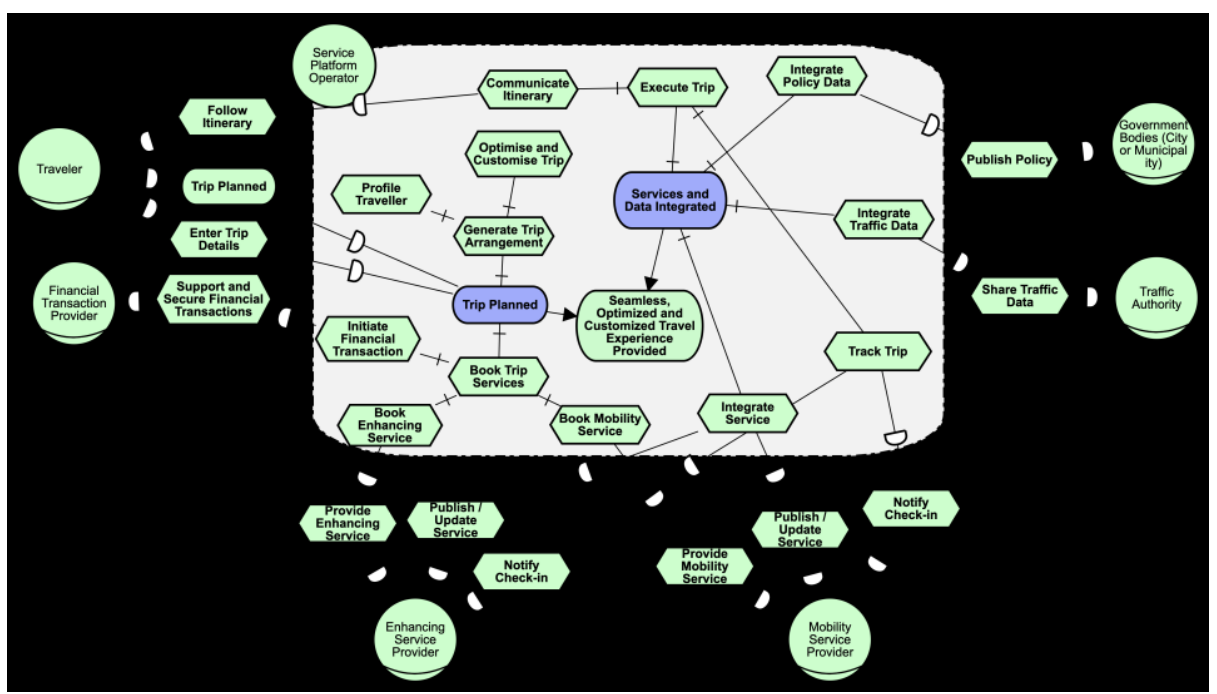

Figure 3: SD-SR Model of the Value Proposition

\section{Application of Step 2:}

Prior to matching the business capabilities to service operations, we defined the business capabilities of the actors through interviews with relevant stakeholders. The resulting list of business capabilities was validated by the same stakeholders (provided at shorturl.at/bjxFH). After defining the business capabilities, we created a service domain for each high-level goal defined in the SR model along with service operations for every task that resides under the high-level goals. We put the defined business capabilities, service domains, and service operations in a Service Domain - Business Capability Matrix as shown in Figure 4. In the matrix, service domains and operations are placed as rows and business capabilities, and the actors owning them are placed as columns. A cell in the matrix is marked with an ' $\mathrm{X}$ ' if the business capability corresponding to the cell facilitates the service operation corresponding to the same cell.

\section{Application of Step 3:}

After identifying the business capabilities, we composed them into business services that are (1) Self-Contained, (2) Stateless, and (3) Representative of a Domain Specific Service. As it is the platform owner of our business case, we focused on the business capabilities of the Service Platform Operator as shown with the red-dashed rectangle in Figure 4. We considered each business capability of the Service Platform Operator as a candidate business service, and we evaluated whether they rely on (1) features or (2) information that reside in another business service and whether they (3) represent a domain specific service. Our evaluation shows that the candidate business services do not need further composition as they are each self-contained, stateless, and representative of a domain specific service. As shown in Figure 4, each coloured cell on the matrix represents a business service that we identified, and the coloured rectangles below the matrix present the names of these business services. 


\section{Application of Step 4:}

After the identification of the business services, we arranged three online meetings with the stakeholders from the Service Platform Operator to select the business services for requirements specification (Activity 4.1). The stakeholders included software platform developers and business analysts. As a result of the meetings, the authors and the stakeholders deemed all 10 business services as feasible and appropriate for requirements specification. Following the selection of the business services, we performed a use case analysis on the business services to specify service requirements in a textual format (Activity 4.2). The resulting use cases are presented in Table 1. Furthermore, the full descriptions of the use cases are provided at (shorturl.at/bjxFH).

Table 1: The List of Use Cases

\begin{tabular}{|c|c|c|}
\hline ID & Use Cases & Description \\
\hline 1 & $\begin{array}{l}\text { Manage } \\
\text { Traveller Profile }\end{array}$ & $\begin{array}{l}\text { This use case defines how travellers can delete, sign-up, or log in } \\
\text { to their account on the service platform. }\end{array}$ \\
\hline 2 & $\begin{array}{l}\text { Manage Serv. } \\
\text { Provider Profile }\end{array}$ & $\begin{array}{l}\text { This use case defines how service providers can delete, sign-up, or } \\
\log \text { in to their account on the service platform. }\end{array}$ \\
\hline 3 & Plan a Trip & $\begin{array}{l}\text { This use case defines how travellers can obtain information about } \\
\text { availability, estimated travel time, and costs. }\end{array}$ \\
\hline 4 & Book a Trip & $\begin{array}{l}\text { This use case defines how the booking of a specific asset for a } \\
\text { specific place, time, and date. }\end{array}$ \\
\hline 5 & Execute a Trip & $\begin{array}{l}\text { This use case defines how travellers can access an asset and a trip } \\
\text { during booked period. }\end{array}$ \\
\hline 6 & Handle Payment & $\begin{array}{l}\text { This use case defines how the settlements between service } \\
\text { providers and service platform operators are closed. }\end{array}$ \\
\hline 7 & $\begin{array}{l}\text { Provide Service } \\
\text { Support }\end{array}$ & $\begin{array}{l}\text { This use case defines how travellers can get assistance in the } \\
\text { solution of operational troubles encountered during any part of the } \\
\text { process. }\end{array}$ \\
\hline 8 & Manage Service & $\begin{array}{l}\text { This use case defines how service providers can manage their } \\
\text { services. }\end{array}$ \\
\hline 9 & $\begin{array}{l}\text { Perform Service } \\
\text { Operations }\end{array}$ & $\begin{array}{l}\text { This use case defines how service providers can monitor and } \\
\text { manage their service operations. }\end{array}$ \\
\hline 10 & $\begin{array}{l}\text { Manage Service } \\
\text { Policy }\end{array}$ & $\begin{array}{l}\text { This use case defines how governing bodies and service platform } \\
\text { operators can communicate with respect to service policies. }\end{array}$ \\
\hline
\end{tabular}

Overall, our application of the Extended VP-BSIM to the business case resulted in the translation of the value proposition of the service system into service platform requirements represented in the form of 10 use cases (Table 1).

\section{Conclusion and Future Work}

In this paper, we have proposed a method designed to guide the identification of platform requirements from value propositions in the form of use case descriptions. Using an SME approach [19], we have constructed the proposed method by extending an existing method. In addition, we have demonstrated the validity of the method by applying it to a business case, where the focus was on the identification of platform 
requirements based on a service system value proposition. The results of our demonstration show that our method guides the derivation of platform requirements from the value propositions. Hence, our study contributes to filling the gap of methodological guidance for the identification of platform requirements from the value propositions in the context of a service system.

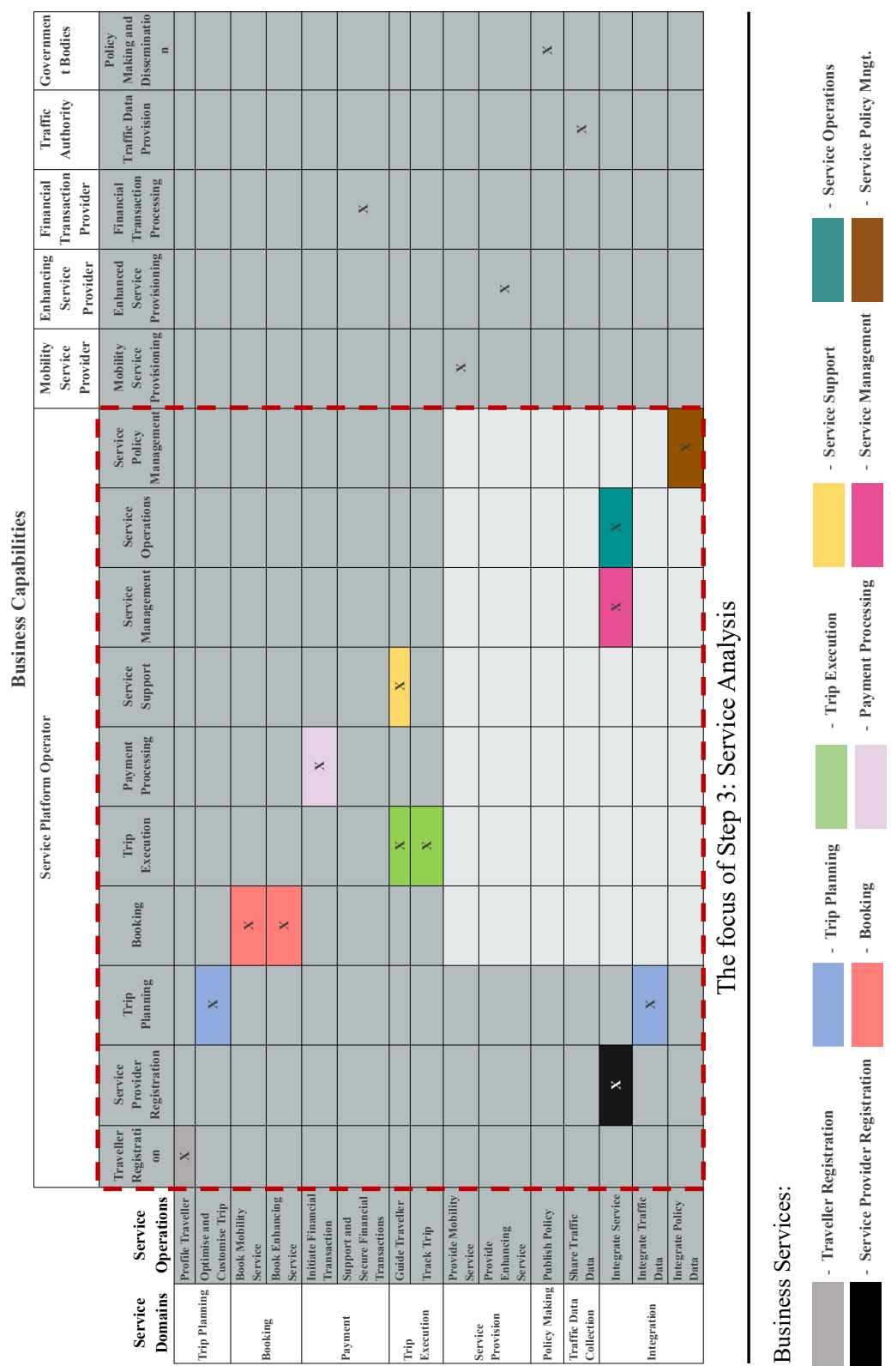

Figure 4: Service Domain - Business Capability Matrix and Business Services 
Our study is subject to limitations rooted in the demonstration strategy we have followed. As such, we have applied our method to a single business case to demonstrate that it can support what it is designed to do (i.e., validity). Additional applications in different business cases and domains are needed to strengthen the evidence with respect to the method's validity. Furthermore, the perceived usefulness of our method (i.e., utility) by its intended users (e.g., business analysts and requirements engineers) remains to be evaluated. Therefore, additional applications should focus on obtaining user feedback on the utility of the method in addition to its validity.

Finally, our method's application to the presented business case should be followed by a longitudinal study that aims at validating that the service platform that is designed by following the service platform requirements defined with our method is operational.

\section{References}

[1] I. Ng and S. Wakenshaw, "Service ecosystems: a timely worldview for a connected, digital and data-driven economy," in The Sage Handbook of Service-Dominant Logic, London: Sage, 2018, pp. 199-213.

[2] S. L. Vargo and R. F. Lusch, "Service-dominant Logic 2025," International Journal of Research in Marketing, vol. 34, no. 1, pp. 46-67, Mar. 2017, doi: 10/f95s3f.

[3] C. F. Breidbach and P. P. Maglio, "Technology-enabled value co-creation: An empirical analysis of actors, resources, and practices," Industrial Marketing Management, vol. 56, pp. 73-85, Jul. 2016, doi: 10/gfc7rp.

[4] C. Engel and P. Ebel, "Data-driven service innovation: a systematic literature review and development of a research agenda," 2019, p. 20.

[5] R. F. Lusch and S. Nambisan, "Service Innovation: A Service-Dominant Logic Perspective," MIS Quarterly, vol. 39, no. 1, pp. 155-175, Jan. 2015, doi: 10.25300/MISQ/2015/39.1.07.

[6] O. Turetken, P. Grefen, R. Gilsing, and O. E. Adali, "Service-Dominant Business Model Design for Digital Innovation in Smart Mobility," Bus Inf Syst Eng, vol. 61, no. 1, pp. 9 29, Feb. 2019, doi: 10/ggkpkp.

[7] C. F. Breidbach and R. J. Brodie, "Engagement platforms in the sharing economy: Conceptual foundations and research directions," Journal of Service Theory and Practice, vol. 27, no. 4, pp. 761-777, Jan. 2017, doi: 10.1108/JSTP-04-2016-0071.

[8] J. A. Fehrer, H. Woratschek, and R. J. Brodie, "A systemic logic for platform business models," Journal of Service Management, vol. 29, no. 4, pp. 546-568, Jan. 2018, doi: 10/gf9p3t.

[9] A. Smedlund, "Value Cocreation in Service Platform Business Models," Service Science, vol. 4, no. 1, pp. 79-88, Mar. 2012, doi: 10.1287/serv.1110.0001.

[10] J. D. Chandler and R. F. Lusch, "Service Systems: A Broadened Framework and Research Agenda on Value Propositions, Engagement, and Service Experience," Journal of Service Research, Jun. 2014, doi: 10/gf74fq.

[11] R. Normann and R. Ramirez, "From value chain to value constellation: Designing interactive strategy.," Harvard business review, vol. 71, no. 4, p. 65, 1993.

[12] M. Blaschke, K. Haki, S. Aier, and R. Winter, "Capabilities for Digital Platform Survival: Insights from a Business-to-Business Digital Platform,” 2018, p. 17.

[13] T. Böhmann, J. M. Leimeister, and K. Möslein, "Service systems engineering," Business and Information Systems Engineering, vol. 6, no. 2, pp. 73-79, 2014, doi: 10.1007/s12599-014-0314-8. 
[14] P. P. Maglio and J. Spohrer, "A service science perspective on business model innovation," Industrial Marketing Management, vol. 42, no. 5, pp. 665-670, 2013.

[15] P. P. Maglio, S. L. Vargo, N. Caswell, and J. Spohrer, "The service system is the basic abstraction of service science," Inf Syst E-Bus Manage, vol. 7, no. 4, pp. 395-406, Sep. 2009, doi: 10.1007/s10257-008-0105-1.

[16] A. Immonen, E. Ovaska, J. Kalaoja, and D. Pakkala, "A service requirements engineering method for a digital service ecosystem," Service Oriented Computing and Applications, vol. 10, no. 2, pp. 151-172, Jun. 2016, doi: 10.1007/s11761-015-0175-0.

[17] O. E. Adali, O. Türetken, B. Ozkan, R. Gilsing, and P. Grefen, "A Multi-concern Method for Identifying Business Services: A Situational Method Engineering Study," in Enterprise, Business-Process and Information Systems Modeling. BPMDS 2020, EMMSAD 2020, France, 2020, pp. 227-241.

[18] L. Lessard, D. Amyot, O. Aswad, and A. Mouttham, "Expanding the nature and scope of requirements for service systems through Service-Dominant Logic: the case of a telemonitoring service," Requirements Eng, vol. 25, no. 3, pp. 273-293, Sep. 2020, doi: 10/ghndjz.

[19] J. Ralyté, R. Deneckère, and C. Rolland, "Towards a Generic Model for Situational Method Engineering," in Advanced Information Systems Engineering, Berlin, Heidelberg, 2003, pp. 95-110.

[20] E. S. K. Yu, Ed., Social modeling for requirements engineering. Cambridge, Mass: MIT Press, 2011.

[21] J. Horkoff et al., "Goal-oriented requirements engineering: an extended systematic mapping study," Requirements Eng, vol. 24, no. 2, pp. 133-160, Jun. 2019, doi: 10.1007/s00766-017-0280-z.

[22] O. E. Adali, B. Ozkan, O. Türetken, R. A. Gilsing, and P. Grefen, "A Method to Transform Value Propositions of a Service System into Business Services, (2021)”. ECIS 2021 Research Papers. 77.

[23] F. Dalpiaz, X. Franch, and J. Horkoff, "iStar 2.0 Language Guide," CoRR, vol. abs/1605.0, 2016.

[24] E. Yu, "Modelling strategic relationships for process reengineering," University of Toronto, 1995. doi: 10.1007/11603412.

[25] T. Kohlborn, A. Korthaus, T. Chan, and M. Rosemann., "Identification and analysis of business and software services-a consolidated approach," IEEE Transactions on Services Computing, vol. 2, no. 1, pp. 50-64, 2009, doi: 10.1109/TSC.2009.6.

[26] S. Jones, "Toward an acceptable definition of service [service-oriented architecture]," IEEE Software, vol. 22, no. 3, pp. 87-93, May 2005, doi: 10.1109/MS.2005.80.

[27] J. Lee, D. Muthig, and M. Naab, "An Approach for Developing Service Oriented Product Lines," 2008 12th International Software Product Line Conference, pp. 275-284, 2008, doi: 10.1109/SPLC.2008.34.

[28] R. Gilsing et al., "Evaluating the Design of Service-Dominant Business Models: A Qualitative Method," Pacific Asia Journal of the Association for Information Systems, vol. 13, no. 1, p. 2, 2021.

[29] E. R. Luftenegger, "Service-Dominant Business Design," Eindhoven University of Technology, 2014. doi: 10.6100/IR774591.

[30] O. Turetken and P. Grefen, "Designing Service-Dominant Business Models," in ECIS 2017 Proceedings, 2017, vol. 2017, pp. 2218-2233. [Online]. Available: http://aisel.aisnet.org/cgi/viewcontent.cgi?article=1140\&context=ecis2017_rp

[31] L. Coconea, V. Mizaras, O. Turetken, G. Dovinola, and P. Grefen, "Insights on traffic management in the MaaS value chain," in 13th ITS European Congress, Jun. 2019, pp. 36. 